New Zealand journal of industrial relations, 1986. 11. 193-195

\title{
Reply to Taylor and Greenslade
}

\author{
Peter Brosnan and Pat Walsh*
}

Replying to this comment by Ray Taylor and Bevan Greenslade (henceforth T \& G) is rather difficult. First, because they were very helpful at different stages of the research and we had hoped would be pleased to see the results. Secondly, because they ascribe motives to us which we did not have and thirdly, because their specific criticisms are in large part based on an inaccurate account of what we actually say in the article. Let us deal with motivation first.

This research project was originally begun by Philip Rowe. the son of the director general of the Employers Federation, while he was a student at Victoria University. The research focus and the contents of the questionnaires were decided in conjunction with staff of the Employers Federation. Peter Brosnan was the official supervisor of the project at the University. Rowe dropped out of university without completing the project. He did however obtain a substantial number of completed questionnaires. Given that there has been virtually no research into the employer side of industrial relations in New Zealand, it was vital that the project be completed.

Brosnan resolved to do this but was committed to other projects and could not resume the work until late 1982. As some time had elapsed, Brosnan resurveyed all IUOEs with Rowe's original questionnaire. An augmented questionnaire was sent to IUOEs affiliated to IAOEs. This latter survey we refer to in Brosnan, Walsh and Rowe 1985 as the "first survey". Brosnan analysed the results during 1984 and prepared the tables used in the article. It had been intended that Rowe would rejoin the project at the writing up phase. However, other commitments and his departure overseas prevented this. His place was taken by Pat Walsh. who joined the project in 1985 and assisted in the writing up phase.

Although each of us had varying degrees of input. the work was done by all three and appears under our joint names. While Brosnan and Walsh wrote up the results, some of the interpretations originated in Rowe's initial study. None of us bears any animus towards the Employers Federation nor, (if indeed one can bear animus against an organisation) any other employer organisations as is alleged in the T \& G comment. Our research focus was not the Federation but rather the IUOEs. The Federation was of interest only insofar as there are a substantial number of IUOEs with their office at the Federation or one of its regional divisions.

Let us deal now with the substantial points raised by T \& G.

(1) They claim that we assume that employer unions are primary bodies in the same way as IUOWs. We make no such assumption. It should be evident from the article that we agree with T \& G that many IUOEs are the alter ego of other employer organisations. In fact. we spend a good part of the article dealing with the relationship of the two bodies. Most of our tables are constructed to highlight the different levels of activity of IUOEs according to whether they are located with a Trade Association and/or the Employers Federation.

(2) T\& G state further "the location of the registered office of an employer union is a matter of custom or convenience for each industry to decide, and no particular conclusions can

* Senior Lecturers in Industrial Relations. Victoria University of Wellington 
be drawn". This bears examination. If they are correct, of the 55 unions not at a trade association, why do 34 choose to have their office at the New Zealand Employers Federation? What customs are involved? In what way is it merely a matter of convenience? In fact, our results show interesting differences in levels of activity according to office location. $T \& \mathrm{G}$ also tend to gloss over the location of many unions at the New Zealand Employers Federation. We never suggest there is anything wrong with this, just that it occurs and is associated with certain patterns of activity, and we try to offer some explanation.

Their whole discussion on these 3 issues is odd. It suggests that we are unaware of the facts when the discussion of them actually forms a large part of our article.

(3) As for their statement that we "admit facts ... as momentous conclusions", i.e. our reporting of the inactivity and subordinate nature of most employer unions, this is their phrase, not ours. We were simply presenting results. This remark of theirs sits oddly with their claim that we assume all employer unions to be primary bodies.

(4) In fact they restate many of our observations as if they were new material, e.g. the idea that union registration is sometimes preserved "as an insurance policy". We not only state this but give a detailed example of one such union.

(5) They castigate us for saying "nothing" of the activities of "primary employer bodies". Our focus was the IUOEs not employer organisations in general.

(6) The selective misreporting of our article is highlighted by their interpretation of our data. They quote the abstract at the head of the article rather than the body of it. Then they claim, on the basis of Tables 1 and 2 , that only 18 out of 122 unions are inactive and that $X^{2}$ tests show there to be no significant difference in activity between those located at the Employers Federation and those located elsewhere. Aside from the questionable use of the $X^{2}$ statistic in this case, there are two non sequitors in this.

First, our conclusions about levels of activity or inactivity were based on the later tables: not Tables 1 and 2 which merely enumerated the population of employer unions and those that were completely inactive.

Secondly, the correct proportion of completely inactive unions is unknown but, based on these Tables 1 and 2, is more like 81 out of 225 , i.e. about a third of all IUOEs.

(7) Their initial assumption that we were motivated by animus leads to some extraordinary conclusions. We are not so deluded to think that anything we might say could affect relations among employer bodies. T \& $\mathrm{G}$ appear to have a surprising belief in the realworld impact of academic articles published in small circulation journals such as this one and, as we commented above, an almost paranoid view of our intentions.

Our remarks about the Employers Federation and the role of its staff in administering IUOEs were merely based on observation, discussions with employers, IUOE members and our data. On the face of it, given the low level of activity we discovered, and which they apparently do not find surprising, it seems perfectly consistent with the conclusions of other studies of bureaucratic organisations to argue that New Zealand Employers Federation staff play a key role in some IUOEs. T \& G offer no opposing evidence to suggest they do not.

(8) Their comments on our discussion on pages 148 and 150 of the article, are most puzzling.

Are they denying the level of influence exercised by the Federation in wage negotiations? Do they think trade associations (through their unions) do not/should not present an alternative perspective? Are they suggesting that all trade associations always agree with the Federation or that a diversity of views is not to be welcomed? Do they claim that the Federation does not "spoon feed" many unions? Their views are obscure.

(9) They deny "that the New Zealand Employers Federation is a monolithic monopoly which stands over other employer bodies". We deny it too. In fact we did so explicitly on page 148 and added that the Federation may not even want such a role if it were available.

In conclusion, we can find little real difference of opinion between T \& G and ourselves. Most of the issues they raise had been treated by us in the article. We claim neither that the New Zealand Employers Federation is omnipotent nor impotent (it cannot be both as they 
state we claim). Our focus was and is the registered employer unions. If they were to abandon the assumption of animus, remarks which they see as an attack on the New Zealand Employers Federation would be seen to be merely interpretations of the questionnaire data and other evidence gathered.

They and we agree that there are IUOEs which are inactive. We know this is a concern which was, and we believe still is. shared by people within the Employers Federation. We go to some length to suggest that IUOEs which are organised directly from the Federation or its regional associations benefit in a number of ways. We are, of course, disappointed that they take exception to our article, but this is an inevitable consequence of objective research in an area as sensitive as industrial relations. 